\title{
COMPARISON OF ACCURACY OF RESTORATIONS GENERATED THROUGH DIGITAL IMAGES OF TWO EXTRA ORAL SCANNERS
}

\author{
Mai Salaheldin*, Ashraf Hussein Sherif** \\ Ahmed Naguib Mohammed ${ }^{* * *}$ and Shereen Ahmed Nossair****
}

\begin{abstract}
Statement of problem: With the advancement of digital technology, extraoral digital scanners have become popular among dental laboratories and dentists. The literature concerning accuracy of restorations fabricated from digital images of extraoral scanners is non conclusive.
\end{abstract}

Aim: The the aim of the study is to compare the accuracy of single crowns generated from CAD/CAM Systems using digital images of two extra-oral scanners.

Materials and Methods: Twenty 3D printed dies were scanned using the investigated extraoral scanners (InEos X5 and Ceramill map 400). The digital images were used to produce a 3D virtual crown design on the systems' respective CAD softwares. Crowns were milled of lithium disilicate blocks. The milled crowns were divided into two groups according to the type of CAD/CAM system used; Group I/M (Cerec system: In Eos X5 and MCX5) and Group C/C (Amanngirbach System: Ceramill map 400 and Ceramill motion2), 10 crowns each. The marginal gap distance between the crown and the 3D printed resin die was measured using a digital microscope and replica technique was used to measure the internal gap between the crowns and their respective $3 \mathrm{D}$ printed resin dies.

Results: Group I/M demonstrated statistically significant smaller median marginal gap distance $95 \mu \mathrm{m}$ while Group C/C demonstrated a median marginal gap distance of $113 \mu \mathrm{m}$. The was no statistically significant difference between both systems with regards to internal fitness. The accuracy of crowns of both systems was within clinically acceptable range.

Conclusions: Crowns generated from CEREC system (In Eos X5/ MCX5) showed better marginal accuracy than AmannGirrbach system. (Ceramill map 400 / Ceramill motion 2). Both systems produced marginal accuracy and internal fitness within the clinically accepted range.

\footnotetext{
* Teaching Assistant, Department of Fixed Prosthodontics, Future University in Egypt

** Professor, Chair, Department of Fixed Prosthodontics, Future University in Egypt

*** Professor, Department of Fixed Prosthodontics, Cairo University

**** Lecturer, Department of Fixed Prosthodontics, Future University in Egypt
} 


\section{INTRODUCTION}

Advances in computer-aided design and manufacturing (CAD/CAM) technology and the concurrent evolution of ceramics, especially zirconia, has led to the substantial increase of CAD/CAM systems in dental clinics and laboratories. ${ }^{1} \mathrm{~A} \mathrm{CAD} /$ CAM system is composed of a digital scanner, a CAD software and a milling unit. ${ }^{2}$ The advantages digital dentistry has to offer includes, time saving, increased patient comfort, decreasing manual labor costs and ultimately improving the fabrication accuracy of dental restorations. ${ }^{3}$

Digital impression systems utilize intraoral scanners (direct digitalization) or extraoral scanners (indirect digitalization). Intraoral scanners eliminate the need for a conventional impression, and its associated possible inaccuracies. ${ }^{4,5,6}$ Although digital casts obtained from an intraoral scanner show high precision and exactness ${ }^{4}$, intraoral digital impressions may be restricted under clinical conditions, resulting in less accuracy for complete-arch casts than those obtained from an extraoral scanner. ${ }^{7,8}$

Extraoral scanning is becoming a common laboratory procedure. Normally, it involves scanning the master models after pouring the impressions of dental preparations made in the dental office. However, with the introduction of high precision extraoral scanners, scanning of dental impressions is also possible. ${ }^{9}$

The fabrication of a crown using CAD/ CAM technology involves three main steps: the digital scanning of the abutment tooth or model, the designing of the restoration, and the actual milling of the crown. In the fabrication of restorations using $\mathrm{CAD} /$ CAM, long-term clinical success ${ }^{10,11}$ depends on the accuracy of the scanners, the designing software and the milling machine, which in turn determines the accuracy of the restoration in terms of marginal and internal fit. ${ }^{12,13,14,15}$

\footnotetext{
* Ivoclar, Vivadent
}

The clinically acceptable limit of marginal gaps according to several authors is generally agreed upon values less than $120 \mu \mathrm{m} .{ }^{16,17,18,19,20}$ Reich et al ${ }^{21}$ proposed that the marginal gaps of the zirconia frameworks used for all-ceramic three-unit fixed dental prosthesis FDP lie between 64 and $83 \mu \mathrm{m}$. Studies comparing accuracy of different digital impression systems have provided varying and controversial results. ${ }^{22,23,24,25,26}$ Shembesh et al ${ }^{27}$ showed that restorations obtained from intraoral digital scanners provide better marginal adaptation compared to restorations from scanning the impression and the master cast. However, these results were encountered with zirconia three-unit FDPs.

Kim et al ${ }^{22}$ Concluded that the conventional impression was significantly more accurate than the iTero digital impression. Flügge et al ${ }^{8}$ found intraoral scanning with the iTero less accurate than model scanning with the iTero, suggesting that the intraoral conditions (saliva, limited spacing) contribute to the inaccuracy of a scan. ${ }^{8}$ Shimizu et al ${ }^{28}$ found the accuracy of both intraoral and extraoral scanners to be clinically acceptable. Marginal and internal fit of the digital crowns fabricated using the intraoral scanner and CAD programs were inferior to those fabricated using the extraoral scanner and CAD programs.

Nevertheless, the current research does not offer direct conclusions regarding the accuracy of crowns generated from digital images of extraoral scanners. Therefore, the purpose of this in vitro study was to evaluate and compare the accuracy of lithium disilicate crowns generated from two widely used CAD/ CAM systems that involve extraoral scanners.

\section{MATERIALS AND METHODS}

A Typodont* cast with a prepared upper first premolar for an all ceramic crown was used for fabrication of the scanning dies. The preparation included; a well-defined circumferential shoulder of $1 \mathrm{~mm}$, a $2 \mathrm{~mm}$ occlusal reduction, 6 degree axial 
inclination, rounded line angles and approximately 1 to $1.5 \mathrm{~mm}$ axial surfaces reduction. The model was scanned with 3Shape lab scanner.* The scan model was ditched on the software and the finish line was highlighted to obtain a clearer view of the finish line margin. The modified scan was then 3D printed into twenty resin dies using Envision TEC $3 \mathrm{D}$ printer.** The twenty stone dies were randomly assigned to two groups $(\mathrm{n}=10)$; where Group I/M (Cerec system) was scanned using In Eos X5 and milled using MCX5, and Group C/C (Amanngirbach System) was scanned using Ceramill map 400 and milled using Ceramill motion2. The twenty crowns were milled out of lithium disilicate (emax CAD) blocks. Table 1 shows the specifications of the two investigated CAD/CAM systems.

Each die was secured carefully on a model holder in the center of the rotation mouse to ensure clear and sharp image without blurring. Scanners were calibrated before scanning. A standardized scan- ning sequence was used to record the preparation according to the manufacturer's instructions. Scanning was initiated at the occlusal surface, continued to the lingual surface and ended at the buccal surface then the image was automatically capture. After identification of the finish line a $3 \mathrm{D}$ virtual design of the crown was chosen from the software library. The cement spacer was set at 60 micron. The milling machines were calibrated and IPS e.max blocks were used to mill the crowns. All e.max CAD crowns underwent a crystallisation cycle according to manufacturer's instructions in Programat P310 (Ivoclar, Vivadent, Schaan, Liechtenstein) ceramic furnace.

\section{Marginal evaluation}

Each specimen was photographed using a digital microscope with a built-in camera (Scope Capture Digital Microscope, Guangdong, China) connected with an IBM compatible personal computer using a

TABLE (1): Specifications of CAD/CAM systems used in this study:

\begin{tabular}{|c|c|c|c|c|}
\hline & Trade Name & description & Specification & Manufacturer \\
\hline \multirow{3}{*}{ CEREC system } & In Eos X5 & $\begin{array}{l}\text { Extra-oral } \\
\text { Scanner }\end{array}$ & $\begin{array}{l}\text { Uses digital stripe projection scanning } \\
\text { technology with Blue light }\end{array}$ & $\begin{array}{l}\text { Dentsply, sirona } \\
\text { ( Germany) }\end{array}$ \\
\hline & $\begin{array}{c}\text { In-Lab CAD } \\
\text { SW } 15.0\end{array}$ & Software & Open architecture & $\begin{array}{c}\text { Dentsply, Sirona } \\
\text { (United states) }\end{array}$ \\
\hline & In lab MCX5 & Milling machine & $\begin{array}{l}\text { Open production unit } \\
\text { Five axes production unit } \\
\text { Dry and wet milling }\end{array}$ & $\begin{array}{c}\text { Dentsply , Sirona } \\
\text { ( United states) }\end{array}$ \\
\hline \multirow{3}{*}{$\begin{array}{l}\text { Amman- } \\
\text { Girrbach system }\end{array}$} & $\begin{array}{l}\text { Ceramill map } \\
\qquad 400\end{array}$ & $\begin{array}{l}\text { Extra-oral } \\
\text { scanner }\end{array}$ & $\begin{array}{c}\text { Uses fully automated stripe light scanning } \\
\text { technology with its high-sensitivity 3D } \\
\text { sensors }\end{array}$ & $\begin{array}{l}\text { AmannGirrbach } \\
\text { (Austria) }\end{array}$ \\
\hline & $\begin{array}{l}\text { Ceramill mind } \\
\text { CAD sw }\end{array}$ & Software & Open architecture & $\begin{array}{l}\text { AmannGirrbach } \\
\text { (Austria) }\end{array}$ \\
\hline & $\begin{array}{l}\text { Ceramill } \\
\text { Motion } 2\end{array}$ & Milling machine & $\begin{array}{l}\text { Open production unit } \\
\text { Five axes production unit } \\
\text { Dry and wet milling }\end{array}$ & AmannGirrbach \\
\hline
\end{tabular}

\footnotetext{
* 3Shape, Copenhagen, Denmark

** Envision TEC, Gladbeck, Germany
} 
fixed magnification of 50X. A digital image analysis system (Image J 1.43U, National Institute of Health, USA) was used to measure and qualitatively evaluate the gap width.

Specimens were held in place over their corresponding dies using a specially designed and fabricated holding device. Shots of the margins were taken for each specimen. Then morphometric measurements were done for each shot at twelve landmarks along the cervical circumference of the specimen (two points on each axial surface and one point on each line angle of the crown) marked on the base of the resin dies. Measurements were recorded at each surface and a total marginal gap value was calculated.

\section{Internal gap evaluation:}

The internal gap was evaluated using replica technique .A polyvinyl siloxane replica of the space between the resin die and the ceramic crown was made for each tested specimen. A light body silicon impression material (Panasil ${ }^{\circledR}$, KETTENBACH,Germany) was injected in the fitting surface of the crown, the crown was then seated under constant occlusal force of $2 \mathrm{~kg}$ controlled by a loading device for 30 seconds. After a total setting of 4 minutes, the crown was separated from the die ,a thin silicone layer attached to the fitting surface of the crown was observed. For the purpose of stabilization of the light body film inside the crown, a heavy poly vinyl siloxane impression material (Panasil@, KETTENBACH,Germany) was injected into the crown. After setting, the two siloxane layers were separated from the crown. Using a razor blade $\left(\mathrm{n}^{\circ} .15 \mathrm{c}\right)$, the replicas were carefully sectioned into four segments and opposite sections were used to measure the internal gap. Seven regions were measured on each section (mid occlusal, axioocclusal, three points on the axial surface, internal margin and external margin), yielding 14 internal measurements for each specimen. Using USB digital microscopy with a built in camera (Scope Capture Digital Microscope, Guangdong, China) at $\times 50$ magnification. The light-body silicone thickness for all replicas was measured, representing the distance between the internal surface of the crown and the external surface of the preparation. Data were recorded, tabulated and statistically analyzed.

Numerical data were explored for normality by checking the distribution of data and using tests of normality (Kolmogorov-Smirnov and Shapiro-Wilk tests). All data showed non-parametric distribution. Data were presented as mean, standard deviation (SD), median and range values. Mann-Whitney U test was used for comparisons between the groups. The significance level was set at $\mathrm{P} \leq 0.05$. Statistical analysis was performed with IBM SPSS Statistics Version 20 for Windows.

\section{RESULTS}

\section{Internal Gap Comparison}

Group I/M produced an internal gap median value of $70.27 \mu \mathrm{m}$, while Group C/C produced internal gap median value of $64.54 \mu \mathrm{m}$. There was no statistically significant difference between median gap distances of the two systems. Figure 1 and Table2 shows median ranges and values of the investigated groups.

\section{Marginal Gap Comparison}

At the mesial, distal as well as buccal surfaces; there was no statistically significant difference between marginal gap distances of the two Groups.

At the lingual surface; I/M Group showed statistically significantly higher median marginal gap distance than C/C Group.

As regards the total marginal gap distance; GroupI/M showed statistically significantly lower median marginal gap distance than Group C/C. Group I/M demonstrated a median marginal gap distance of $95 \mu \mathrm{m}$ while Group C/C demonstrated a median marginal gap distance of $113 \mu \mathrm{m}$. Table 3 and Figure 2 show median ranges of the investigated groups. 
TABLE (2) The median, range values and results of Mann-Whitney $U$ test for comparison between gap distances of the two home milling techniques

\begin{tabular}{|c|c|c|c|c|c|c|c|}
\hline \multicolumn{3}{|c|}{$\mathrm{I} / \mathrm{M}$} & \multicolumn{3}{|c|}{$\mathrm{C} / \mathrm{C}$} & \multirow{2}{*}{ P-value } & \multirow{2}{*}{$\begin{array}{l}\text { Effect } \\
\text { size }(r)\end{array}$} \\
\hline Median & Minimum & Maximum & Median & Minimum & Maximum & & \\
\hline 70.27 & 40.1 & 203.8 & 64.54 & 56.15 & 122.87 & 0.927 & 0.017 \\
\hline
\end{tabular}

*: Significant at $P \leq 0.05$

TABLE (3) The median, range values and results of Mann-Whitney U test for comparison between marginal gap distances of the two home milling techniques

\begin{tabular}{|c|c|c|c|c|c|c|c|c|}
\hline \multirow[b]{2}{*}{ Surface } & \multicolumn{3}{|c|}{$\mathrm{I} / \mathrm{M}$} & \multicolumn{3}{|c|}{$\mathrm{C} / \mathrm{C}$} & \multirow{2}{*}{ P-value } & \multirow{2}{*}{$\begin{array}{c}\text { Effect size } \\
\text { (r) }\end{array}$} \\
\hline & Median & Minimum & Maximum & Median & Minimum & Maximum & & \\
\hline Mesial & 0.077 & 0.061 & 0.11 & 0.105 & 0.083 & 0.132 & 0.116 & 0.497 \\
\hline Distal & 0.107 & 0.092 & 0.116 & 0.095 & 0.078 & 0.119 & 0.347 & 0.110 \\
\hline Buccal & 0.094 & 0.048 & 0.149 & 0.141 & 0.07 & 0.15 & 0.249 & 0.079 \\
\hline Lingual & 0.117 & 0.079 & 0.121 & 0.129 & 0.124 & 0.149 & $0.009 *$ & 0.828 \\
\hline Total & 0.095 & 0.083 & 0.106 & 0.113 & 0.099 & 0.125 & $0.008 *$ & 0.693 \\
\hline
\end{tabular}

*: Significant at $P \leq 0.05$

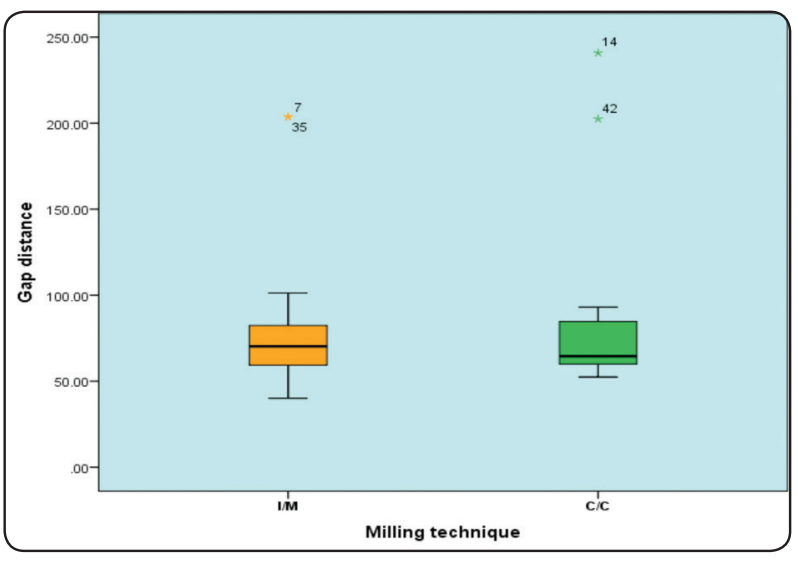

Fig. (1). Box plot representing median and range values for gap distances of the two home milling techniques (Stars represent outliers)

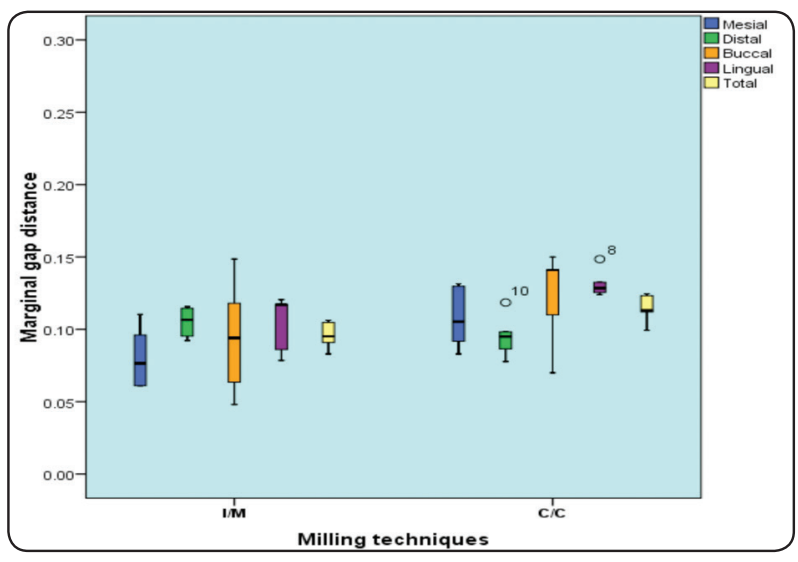

Fig. (2). Box plot representing median and range values for marginal gap distances of the two home milling techniques (Circles represent outliers) 


\section{DISCUSSION}

In this study, the two investigated systems are widely used and share a similar milling technology. Three-dimensional printed resin dies were used in this study, for the sake of standardization and to provide a more dimensionally stable die for use during scanning and testing procedures of the milled crowns. Single upper premolar dies were used to examine the accuracy of restorations with anatomical occlusal morphology and to limit the scan area to avoid the complications associated with scanning larger span areas..$^{29}$ Lithium disilicate was used for fabrication of crowns because of its relative popularity as a ceramic material of choice for single restorations, and to avoid any associated discrepancies accompanying the sintering of zirconia. ${ }^{30}$

The longevity of restorations is directly related to its accuracy, in terms of marginal and internal fitness. ${ }^{31}$ Good marginal adaptation prevents cement dissolution and consequent caries and discoloration..$^{32}$ An improved internal adaptation provides better retention, strength, and resistance of the restoration. $^{33,34}$ Hence, marginal and internal fitness were measured to validate the accuracy of extraoral scanners.

Different methods have been used to assess the marginal and internal fit of the restorations. In this study the silicone replica technique was used, a popular non-destructive method to assess the marginal and internal fit in vitro. The silicon replica technique is considerably easy ${ }^{35}$ and reliable ${ }^{36}$. On the other hand, the difficulty in identifying the margins of the restoration, possible tearing of the silicone film upon removal of the crown, as well as sectioning plane error and few reference points are considered drawbacks of the silicone replica technique. ${ }^{37}$

Other methods include the cross-sectioning method where direct measurement of the cement thickness and marginal gap in the vertical and horizontal planes is performed. It is however, a destructive method and the number of measurements is limited to the sectioning plane, which might not represent the complete fit of the crown ${ }^{38}$. Profilometry, another nondestructive method, presents a view of both the die and the specimen in the same focal plane on a monitor, thus allowing for an accurate focus. However, extreme care should be taken in repositioning the specimens, to avoid re-profiling discrepancies ${ }^{39}$ Remaining methods, including digimatic micro-meter and micro-CT scan, which have attracted the least attention, mainly due to inherent technical difficulties. ${ }^{38}$

Regarding the marginal gap, there are various testing methods and measuring tools, the direct view method using the digital microscope is considered more convenient, accurate, easy and rapid for determining the marginal gap distance and the crown is retrievable, unlike cementation, embedment and sectioning method that causes destruction of the crown. ${ }^{40}$

The results of this study demonstrated that both CAD/CAM systems used were able to produce crowns with marginal and internal fitness within clinically acceptable ranges. Their marginal gap median ranged from 95-113 $\mu \mathrm{m}$ while the internal gap ranged from 64.5-70.2 $\mu \mathrm{m}$.

Group I/M demonstrated better marginal accuracy than Group C/C. The type of CAD/CAM system is an influential factor in the accuracy of the scanners. ${ }^{341}$

The improved marginal accuracy obtained with the CEREC system in relation to AmmanGirrbach are in agreement with Emir et $\mathrm{al}^{42}$ who evaluated the accuracy of eight different extraoral laboratory scanners using three-dimensional (3D) analysis method. The authors concluded that scanners using blue-light including In EosX5 showed more accurate results than the white-light as Ceramill Map 400. These results were also confirmed with Salem et al ${ }^{43}$ who reported that the crowns scanned with In Eos X5 (home milling I/M ) showed significantly better marginal fit of lithium disilicate crowns with a mean 
value of $76 \pm 39.0 \mu \mathrm{m}$. The type of ceramic may be another factor that effects the marginal accuracy of crowns made with a CAD/CAM technique ${ }^{29}$. The improved accuracy of CEREC system is consistent with Ender et al ${ }^{44}$, who reported a higher accuracy of scans obtained from In Eos X5 scanner in comparison to eight different intra-oral scanners.

The clinically acceptable marginal and internal fit results obtained in this study are a result of the entire $\mathrm{CAD} / \mathrm{CAM}$ workflow, including the scanning and milling. The nature of the milling units of the investigated CAD/CAM systems; 5-axis milling machine, has been reported to show superior performance in internal adaptation of milled restorations. ${ }^{45}$ The higher the number of milling axes, the better the ability to rotate the milling spindle, thereby leading to greater accuracy. This could be connected to a better finishing in the cervical region of the restoration that has a consequent impact on marginal adaptation. The smaller and more diverse size of the milling burs used in the milling units may also contribute to the more accurate milling procedure. ${ }^{46}$

The variations in marginal gap values at different surfaces obtained in this study, may be due to errors inherent to the technologies employed and the software systems used to process the images as reported by Porter et al. ${ }^{47}$ The presence of small irregularities on the surface may have also contributed to the lower marginal accuracy noted with certain surfaces in this study. Gonzalez de Villaumbrosia et $\mathrm{al}^{48}$ stated that the entire scanning procedure is more accurate if the scanned surfaces are smooth and regular.

Currently, some highly precise extraoral digital impression techniques are available that present highly similar results for marginal fit. The results are even better when compared with those of intraoral digital impressions when longer lengths in the arch are scanned. ${ }^{8}$ Crowns fabricated using in-lab CAD/CAM systems, that use extra-oral scanners have been reported to show better marginal and internal fit than in-office systems that use the intraoral scanners. ${ }^{27}$ Direct digital scanning of a model is usually better than intraoral scanning that is more difficult, especially since the exposure time should be short enough to prevent a blurred scan. ${ }^{49}$ The size of the camera for scanning in the mouth is also an important factor because the intraoral optical scanning device should be able to enter the patient's mouth further up to the posterior area so that it can cover all the teeth, including the second and third molars. The favorable performance of in-lab CAD/CAM systems using extra-oral scanners was also supported by Brawek et $\mathrm{al}^{5}$ who compared the marginal fit of two extra-oral CAD/CAM systems, Lava and CEREC AC/In lab, with the conventional technique to find that all digitally fabricated crowns were within the clinically acceptable range.

The results of this study validate the accuracy of crowns generated from CAD/CAM systems that use extraoral scanners.

\section{CONCLUSION}

The two investigated CAD/CAM systems using extraoral scanners were able to produce crowns with clinically acceptable marginal and internal fitness.

The crowns generated from InEos X5 scanner and MCXL milling system demonstrated improved marginal accuracy than those of the Ceramill map 400 scanner and Ceramill motion2 milling system. The two systems showed comparable internal fitness.

\section{REFERENCES}

1 Strub J, Rekow E, Witkowski S. Computer-aided design and fabrication of dental restorations. J Am Dent Assoc 2006;137:1289-96.

2 Kapos T, Evans C. CAD/CAM technology for implant abutments, crowns, and superstructures. Int J Oral Maxillofac Implants 2014;29(Suppl):117-36.

3 Renne W, Ludlow M, Fryml J, Schurch Z, Mennito A, Kessler R, Lauer A. Evaluation of the accuracy of 7 digital scanners: An in vitro analysis based on 3-dimensional comparisons J Prosthet Dent. 2017 Jul; 118(1):36-42. 
4 Guth JF, Keul C, Stimmelmayr M, Beuer F, Edelhoff D. Accuracy of digital models obtained by direct and indirect data capturing. Clin Oral Investig. 2013 May; 17(4):1201-8.

5 Brawek PK, Wolfart S, Endres L, Kirsten A, Reich S. The clinical accuracy of single crowns exclusively fabricated by digital workflow-the comparison of two systems. Clin Oral Investig. 2013 Dec;17(9):2119-25.

6 Rudolph H, Salmen H, Moldan M, Kuhn K, Sichwardt V, Wostmann B, et al. Accuracy of intraoral and extraoral digital data acquisition for dental restorations. J Appl Oral Sci. 2016; 24(1):85-94.

7 Karl m. In vitro studies on CAD/CAM restorations fabricated with Procera technology: an overview. Quintessence Int. 2015; 46(7): 561-74

8 Flügge TV, Schlager S, Nelson K, Nahles S, Metzger MC Precision of intraoral digital dental impressions with iTero and extraoral digitization with the iTero and a model scanner. Am J Orthod Dentofacial Orthop. 2013 ; 144(3):471-8.

9 Aranda Yus, Cantarell JMA, Miñarro Alonso A.Comparison of the marginal fit of milled yttrium stabilized zirconium dioxide crowns obtained by scanning silicone impressions and by scanning stone replicas. J Adv Prosthodont 2018;10:236-44

10 Molin MK, Karlsson SL. A randomized 5-year clinical evaluation of 3 ceramic inlay systems. Int J Prosthodont 2000; 13: 194-200.

11 Sailer I, FehérA, Filser F, Gauckler LJ, Lüthy H, Hämmerle $\mathrm{CH}$. Five-year clinical results of zirconia frameworks for posterior fixed partial dentures. Int J Prosthodont 2007; 20: 383-388.

12 Jacobs MS, Winder AS. An investigation of dental luting cement solubility as a function of the marginal gap. $\mathrm{J}$ Prosthet Dent 1991; 65: 436-442.

13 Sachs C, Groesser J, Stadelmann M, Schweiger J, Erdelt $\mathrm{K}$, Beuer F. Full-arch prosthesis from translucent zirconia: accuracy of fit. Dent Mater 2014; 30: 817-823.

14 Keul C, Stawarczyk B, Erdelt KJ, Beuer F, Edelhoff D, Güth JF. Fit of 4-unit FDPs made of zirconia and CoCralloy after chairside and labside digitalization - a laboratory study. Dent Mater 2014; 30: 400-407.

15 Mously HA, Finkelman M, Zandparsa R, Hirayama H. Marginal and internal adaptation of ceramic crown restorations fabricated with CAD/CAM technology and the heat-press technique. J Prosthet Dent 2014; 112: 249-256.
16 Iwai, T, Komine, F, Kobayashi, K, et al: Influence of convergence angle and cement space on adaptation of zirconium dioxide ceramic copings. Acta Odontol Scand 2008; 66: $214-218$

17 Quintas, AF, Oliveira, F, Bottino, MA: Vertical marginal discrepancy of ceramic copings with different ceramic materials, finish lines, and luting agents: an in vitro evaluation. J Prosthet Dent 2004; 92: 250- 257

18 Wolfart, S, Wegner, SM, Al-Halabi, A, et al: Clinical evaluation of marginal fit of a new experimental all-ceramic system before and after cementation. Int J Prosthodont 2003; 16: 587-592

19 Bindl, A, Mormann, WH: Marginal and internal fit of allceramic CAD/CAM crown-copings on chamfer preparations. J Oral Rehabil 2005; 32: 441-447

20 Sailer, I, Fehér, A, Filser, F, et al: Five-year clinical results of zirconia frameworks for posterior fixed partial dentures. Int J Prosthodont 2007; 20: 383-388

21 Reich, S, Wichmann, M, Nkenke, E, et al: Clinical fit of all-ceramic three-unit fixed partial dentures, generated with three different CAD/CAM systems. Eur J Oral Sci 2005; 113: 174- 179

22 Kim SY, Kim MJ, Han JS, et al: Accuracy of an intraoral digital impression using parallel confocal imaging. Int $\mathbf{J}$ Prosthodont 2013;26:161-163

23 Syrek A, Reich G, Ranftl D, et al: Clinical evaluation of all-ceramic crowns fabricated from intraoral digital impressions based on the principle of active wavefront sampling. J Dent 2010;38:553-559

24 Luthardt RG, Loos R, Quaas S: Accuracy of intraoral data acquisition in comparison to the conventional impression. Int J Comput Dent 2005;4:283-294

25 Gonzalo E, Sua 'rez MJ, Serrano B, et al: A comparison of the marginal vertical discrepancies of zirconium and metal ceramic posterior fixed dental prostheses before and after cementation. J Prosthet Dent 2009;6:378-384

26 Banday O, Nathanson D: Determining the accuracy of a CAD-CAM milled polyurethane die system (Cadent iTero) derived from optical-digital impressions. Master Thesis, Boston University 2011;55-69

27 Marwa Shembesh,, Ala Ali, Matthew Finkelman, HansPeter Weber and Roya Zandparsa. An In Vitro Comparison of the Marginal Adaptation Accuracy of CAD/CAM Restorations Using Different Impression Systems Journal of Prosthodontics 26 (2017) 581-586 
28 Shimizu S, Shinya A, Kuroda S, Gomi H. The accuracy of the CAD system using intraoral and extraoral scanners for designing of fixed dental prostheses. Dent Mater J. 2017 26;36(4):402-407.

$29 \mathrm{Su}$ TS, Sun J. Comparison of repeatability between intraoral digital scanner and extraoral digital scanner: An in-vitro study. Journal of prosthodontic research. 2015;59(4):236-42.

30 Stawarczyk B, Ozcan M, Hallmann L, Ender A, Mehl A, Hammerlet $\mathrm{CH}$. The effect of zirconia sintering temperature on flexural strength, grain size, and contrast ratio. Clinical oral investigations. 2013;17(1):269-74.

31 Sjogren, G., 1995, Marginal and internal fit of four different types of ceramic inlays after luting. An in vitro study. Acta Odontologica Scandinavica. 53(1):24-8.

32 Yildiz C, Vanlioglu BA, Evren B, Uludamar A, Ozkan YK. Marginal-internal adaptation and fracture resistance of CAD/CAM crown restorations. Dental materials journal. 2013;32(1):42-7.

33 Anadioti E, Aquilino SA, Gratton DG, Holloway JA, Denry IL, Thomas GW, et al. Internal fit of pressed and computer-aided design/computer-aided manufacturing ceramic crowns made from digital and conventional impressions. The Journal of prosthetic dentistry. 2015;113(4):3049.

34 Sakrana AA. In vitro evaluation of the marginal and internal discrepancies of different esthetic restorations. Journal of applied oral science : 2013;21(6):575-80.

35 An S, Kim S, Choi H, Lee JH, Moon HS. Evaluating the marginal fit of zirconia copings with digital impressions with an intraoral digital scanner. The Journal of prosthetic dentistry. 2014;112(5):1171-5.

36 Rahme HY, Tehini GE, Adib SM, Ardo AS, Rifai KT. In vitro evaluation of the "replica technique" in the measurement of the fit of Procera crowns. The journal of contemporary dental practice. 2008;9(2):25-32.

37 Nawafleh NA, Mack F, Evans J, Mackay J, Hatamleh MM. Accuracy and reliability of methods to measure marginal adaptation of crowns and FDPs: a literature review. Journal of prosthodontics : official journal of the American College of Prosthodontists. 2013;22(5):419-28.

38 Mitchell CA, Pintado MR, Douglas WH. Nondestructive, in vitro quantification of crown margins. The Journal of prosthetic dentistry. 2001;85(6):575-84.
39 Good M-L, Mitchell CA, Pintado MR, Douglas WH. Quantification of all-ceramic crown margin surface profile from try-in to 1-week post-cementation. Journal of dentistry. 2009;37(1):65-75.

40 Sorensen JA. A standardized method for determination of crown margin fidelity. The Journal of prosthetic dentistry. 1990;64(1):18-24.

41 Hamza TA, Ezzat HA, El-Hossary MM, Katamish HA, Shokry TE, Rosenstiel SF. Accuracy of ceramic restorations made with two CAD/CAM systems. J Prosthet Dent. 2013 Feb; 109(2):83-7.

42 Emir F, Ayyildiz S. Evaluation of the trueness and precision of eight extraoral laboratory scanners with a complete-arch model: a three-dimensional analysis. Journal of prosthodontic research. 2019 (Epub ahead of Print).

43 Salem M, Abdel kader S, Al Abassy F, Azer A. Evaluation of fit accuracy of computer-aided design/computer-aided manufacturing crowns fabricated by three different digital impression techniques using cone-beam computerized tomography.2016: 4(2): 32-36

44 Ender A,Zimmermann M, Mehl A. Accuracy of completeand partial-arch impressions of actual intraoral scanning systems in vitro. Int J Comput Dent. 2019;22(1):11-9.

45 Alajaji NK, Bardwell D, Finkelman M, Ali A. Micro-CT Evaluation of Ceramic Inlays: Comparison of the Marginal and Internal Fit of Five and Three Axis CAM Systems with a Heat Press Technique. Journal of esthetic and restorative dentistry : official publication of the American Academy of Esthetic Dentistry. 2017;29(1):49-58.

46 Kricheldorf F, Bueno CRS, Amaral WDS, Junior JFS, Filho HN. Analysis of vertical marginal discrepancy in feldspathic porcelain crowns manufactured with different CAD/CAM systems: Closed and open. European journal of dentistry. 2018;12(1):123-8.

47 Porter JL, Carrico CK. Comparison of intraoral and extraoral scanners on the accuracy of digital model articulation. 2018;45(4):275-82.

48 Gonzalez de Villaumbrosia P, Martinez-Rus F, GarciaOrejas A, Salido MP, Pradies G. In vitro comparison of the accuracy (trueness and precision) of six extraoral dental scanners with different scanning technologies. The Journal of prosthetic dentistry. 2016;116(4):543-50.

49 Mehl A, Ender A, Mormann W, Attin T. Accuracy testing of a new intraoral 3D camera. Int $\mathrm{J}$ Comput Dent. 2009;12(1):11-28. 